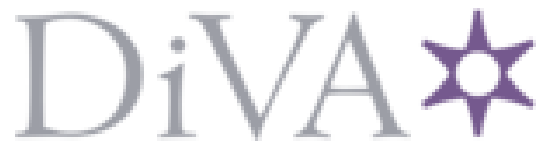

http://www.diva-portal.org

This is the published version of a paper published in Energy Efficiency.

Citation for the original published paper (version of record):

Brembilla, C., Vuolle, M., Östin, R., Olofsson, T. (2017)

Practical support for evaluating efficiency factors of a space heating system in cold climates: modelling and simulation of hydronic panel radiator with different location of connection pipes

Energy Efficiency, 10(5): 1253-1267

https://doi.org/10.1007/s12053-017-9506-7

Access to the published version may require subscription.

N.B. When citing this work, cite the original published paper.

Permanent link to this version:

http://urn.kb.se/resolve?urn=urn:nbn:se:umu:diva-121199 


\title{
Practical support for evaluating efficiency factors of a space heating system in cold climates
}

\author{
Modelling and simulation of hydronic panel radiator with different location \\ of connection pipes
}

\author{
Christian Brembilla • Mika Vuolle • Ronny Östin • \\ Thoms Olofsson
}

Received: 12 April 2016 / Accepted: 16 January 2017 / Published online: 3 April 2017

(C) The Author(s) 2017. This article is published with open access at Springerlink.com

\begin{abstract}
Plenty of technical norms, included in the EPBD umbrella, assesses the performance of buildings or its sub-systems in terms of efficiency. In particular, EN 15316 and its sub-sections determine the efficiency factors of a space heating system. This paper focuses on the estimation of efficiency factors for hydronic panel radiators. The assessment of efficiency factors occurs by evaluating the amount of heat emitted from the heat emitter and the thermal losses towards building envelope. A factor that influences the heat emitted is the location of radiator connection pipes. Connection pipes can be located on opposite side or at the same side of the radiator. To better estimate the heat emitted from the radiator with different location of connection pipes, a transient model with multiple storage elements is implemented in a commercial building simulation software and validated versus available experimental measurements. Sensitivity analysis encompasses the variations of heat losses due to the building location in different
\end{abstract}

C. Brembilla $(\bowtie) \cdot$ R. Östin $\cdot$ T. Olofsson

Department of Applied Physics and Electronics (TFE),

Umeå University, X, Håken Gullessons väg, 20, 90 187,

Umeå, Sweden

e-mail: christian.brembilla@umu.se

M. Vuolle

EQUA Simulation Finland Oy, Keskiyönkatu 3 A 1, 02210

Espoo, Finland climates, the changing of the active thermal mass and the type of radiator local control. The final outcome of this paper is a practical support where designers and researchers can easily assess the efficiency factors for space heating system equipped with hydronic panel radiators of buildings located in Sweden. As main results, (i) the efficiency factor for control is higher in Northern climates (Luleå) than in Southern climates (Gothenburg), (ii) heavy-weight active thermal masses allow higher efficiency factors than light active thermal masses, and (iii) connection pipes located on the same side of the hydronic panel radiator enable higher efficiency factors than pipes located on opposite side.

Keywords Hydronic panel radiator - Efficiency factors - Connection pipes · Transient model with multiple storage elements $\cdot$ Climate $\cdot$ Active thermal mass

\section{Nomenclature}

Symbols

$\begin{array}{lll}\dot{m} & \text { Mass flow rate } & \mathrm{kgs}^{-1} \\ \mathrm{H} & \text { Radiator hight } & \mathrm{m} \\ \mathrm{L} & \text { Radiator length } & \mathrm{m} \\ \mathrm{Q} & \text { Heat loss } & \mathrm{kWh} \\ \mathrm{T} & \text { Temperature } & \mathrm{K}\end{array}$




$\begin{array}{lll}\alpha, \beta & \text { Coefficients } & \\ \triangle \theta & \text { Time step } & \mathrm{s} \\ \dot{Q} & \text { Heat flow/ heat transfer rate } & \mathrm{W} \\ \eta & \text { Efficiency factor } & \\ \lambda & \text { Air heat conductivity } & \mathrm{Wm}^{-1} \mathrm{~K}^{-1} \\ \phi & \text { Relative humidity } & \% \\ \rho & \text { Density } & \mathrm{kg} \mathrm{m}^{-3} \\ \mathrm{~A} & \text { Surface area } & \mathrm{m}^{2} \\ \mathrm{~b} & \text { Channel thickness } & \mathrm{m} \\ \text { cloud } & \text { Cloudiness } & \% \\ \mathrm{C} & \text { Capacitance } & \mathrm{JK}^{-1} \\ \mathrm{c} & \text { Specific heat capacity } & \mathrm{Jkg}^{-1} \mathrm{~K}^{-1} \\ \mathrm{~d} & \text { Diffuse radiation } & \mathrm{Wm}^{-2} \\ \mathrm{~d} & \text { Direct radiation } & \mathrm{Wm}^{-2} \\ \mathrm{Gr} & \text { Grashof number } & \\ \mathrm{K} & \text { Total heat transfer coefficient } & \mathrm{Wm}^{-2} \mathrm{~K}^{-1} \\ \mathrm{M} & \text { Mass } & \mathrm{kg}^{-1} \\ \mathrm{nCap} & \text { Number of capacitance } & \\ \mathrm{Nu} & \text { Nusselt number } & \\ \mathrm{Pr} & \text { Prandtl number } & \\ \mathrm{U} & \text { Thermal transmittance } & \mathrm{Wm}^{-2} \mathrm{~K}^{-1} \\ \mathrm{v} & \text { Wind velocity } & \mathrm{ms}^{-1} \\ & & \end{array}$

\section{Subscripts}

$\begin{array}{ll}\text { air } & \text { Air } \\ \text { back-wall } & \text { Back-wall } \\ \text { brick } & \text { Brick } \\ \text { cei } & \text { Ceiling } \\ \text { conv } & \text { Convective } \\ \text { con } & \text { Concrete } \\ \text { ctrl } & \text { Control } \\ \text { embed } & \text { Embedded system } \\ \text { em } & \text { Emission } \\ \text { exh } & \text { Exhaust } \\ \text { fld } & \text { Fluid (liquid) } \\ \text { front } & \text { Front towards the room } \\ \text { ideal } & \text { Ideal } \\ \text { inc } & \text { Increased/decreased } \\ \text { ln } & \text { Logarithmic } \\ \text { met } & \text { Metal } \\ \mathrm{N} & \text { Nominal } \\ \text { out } & \text { Outdoor } \\ \text { set } & \text { Set-point } \\ \text { str } & \text { Stratification } \\ \text { sup } & \text { Supply } \\ \text { surf } & \text { Radiator surface } \\ \text { tot } & \text { Total } \\ \text { win } & \text { Window } \\ \text { wood } & \text { Wood } \\ & \end{array}$

\section{Superscripts}

n Radiator exponent

\section{Acronyms}

ICE Indoor climate and energy

IDA Implicit Differential Algebraic equations solver

$\mathrm{ACH}$ Air Change per Hour

EPBD Energy Performance of Buildings Directive

HVAC Heating Ventilation Air Conditioning

PI Proportional Integral

\section{Introduction}

According to EN 15316-1 (2007), the efficiency in buildings is a performance indicator of space heating system or its sub-systems (the hydronic radiator) which "serves as practical and straightforward comparison of effectiveness of systems or sub-systems of different types and/or different sizes".

This paper is focused on the efficiency factors (extensively explained in the "Method to calculate the efficiency factors for free heating surface (radiator) according to EN 15316-1,2-1 (2007) named as "German Method"” section of a space heating system when the heat emitter is a hydronic panel radiator.

Recent studies proposed by Maivel and Kurnitski (2014) have investigated efficiency factors of the heating systems according to EN 15316-1 (2007) and EN 15316-2-1 (2007). The values of efficiency factors were referred to different house typologies (detached houses and apartments) located in different climates. The buildings were modelled by using dynamic building energy simulation software with careful attention to the thermal losses of the distribution system and the hydronic radiator was modelled with steady state model.

According to Myers (1971), steady state models suffer from some serious limitations, for instance, they do not consider the heat stored in the thermal unit. Instead, a transient model stores thermal energy into the thermal mass which is released later towards the indoor environment. Tahersima et al. $(2010,2013)$ show a transient model of radiator in which both temperature of exhaust flow and heat emitted are time dependent and they evolve during the charging/discharging phases of the radiator. The heat 
emitted influences the behaviour of room temperature, which is an essential parameter to calculate the thermal losses through the building envelope.

Stephan (1991) and Holst (1996) showed a simulation model of hydronic panel radiator where the total heat transferred towards the environment depends on the amount of mass flow rate. In fact, when the mass flow rate supplied was less than $2 \%$ of the nominal mass flow rate $\left(\dot{\mathrm{m}}_{\mathrm{fld}}<0.02 \dot{\mathrm{m}}_{\mathrm{fld}, \mathrm{N}}\right)$ with $\left(\mathrm{T}_{\text {sup }, \mathrm{n}}=\right.$ $90^{\circ} \mathrm{C}, \mathrm{T}_{\text {exh, } \mathrm{n}}=70^{\circ} \mathrm{C}, \mathrm{T}_{\text {air, } \mathrm{n}}=20^{\circ} \mathrm{C}$ ), the temperature of exhaust flow is equal to the indoor temperature and the calculations of the heat emitted are equal to the heat supplied to the thermal unit.

Furthermore, hydronic panel radiators have different location of connection pipes. For example, Fig. 1a shows the structure of a panel radiator when the connection pipes are located on the same side and Fig. $1 \mathrm{~b}$ when connection pipes are located on the opposite side. The location of connection pipes does not affect the way of the hydronic panel radiator is physically built but the way in which the heat is emitted towards the environment. In fact, the hydronic panel radiators presented are made with two horizontal channels (supply and exhaust lines) connected by vertical pipes. These two types of hydronic panel radiator will be analysed in the current paper.

Connection pipes positioned at the same side make the charging process of the panel from left to right or vice-versa as shown in Brembilla et al. (2015a). It is possible to notice in Fig. 2a, b the supply flow enters into the top right corner, it drops down along the pipe lines and exiting from the bottom right corner.

Jančik and Bašta (2012) show in their study a hydronic panel radiator with connection pipes located on opposite side. The heat was supplied on the top left corner and the outlet pipe was located on the bottom right corner. The thermal imaging shows how the heat is distributed on the panel surface and most likely the charging phase of this type of radiator is performed from top towards down.

According to the previous studies, there is little research which assesses the heat emitted from hydronic panel radiators connected with different location of connection pipes.

A sophisticated model of hydronic panel radiator is needed to encompass details that influence the heat emitted from the radiator and consequently affect the efficiency factors.

The scope of this paper is to determine efficiency factors for a space heating system equipped with hydronic panel radiators and to compare them among different technical choices for buildings located in Sweden. This paper clarifies which type of connection pipes, located on the same or on the opposite side of the hydronic panel radiator, provides the best efficiency factors for a space heating system. To achieve this goal, a transient model of radiator with multiple storage elements, based on the merge of two existing models developed by Bring et al. (1999) and Brembilla et al. (2015a), is programmed in IDA ICE vers. 4.7 environment. The hydronic panel radiator model takes into account: thermal energy stored in the thermal mass, time of charging/discharging of thermal unit, thermal losses towards the radiator back wall, convective and radiative heat from the hydronic panel radiator and location of connection pipes. The hydronic panel radiator model is then applied to a building simulation model of a room to calculate the thermal losses towards building envelope and the efficiency factors. The main result is a table filled by values of efficiency factors proposed as more comprehensive and detailed approach on this topic.

\section{Methodology}

This section explains the methodology used to assess the thermal losses towards building envelope and to calculate the efficiency factors among different hydronic panel radiators. In particular, the "Method to calculate the efficiency factors for free heating surface (radiator) according to EN 15316-1,2-1 (2007) named as "German Method"” section explains how to compute the thermal losses and the efficiency factors
Fig. 1 Location of connection pipes. a Same side. b Opposite side
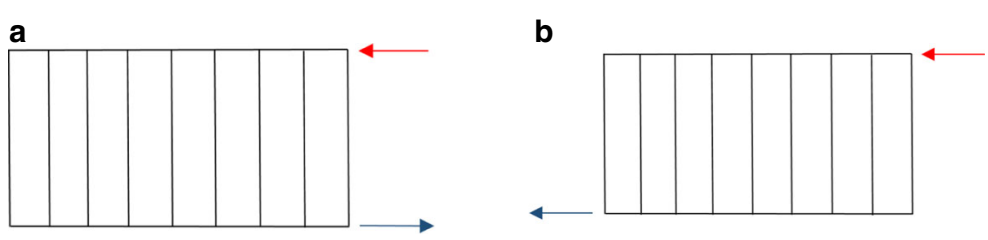
Fig. 2 Charging sequence of hydronic panel radiator taken from Brembilla et al. (2015a). a 18:45:15. b 18:51:15 a

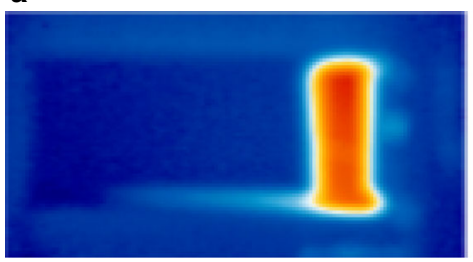

$18: 45: 15$ b

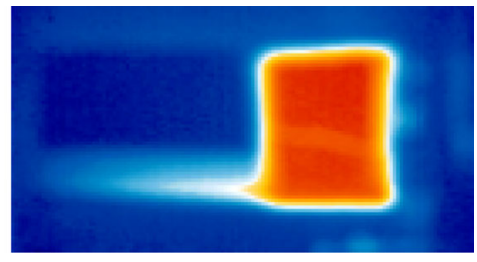

$18: 51: 15$ of radiators. The "Transient model of the hydronic panel radiator" section introduces the transient model of the hydronic panel radiator used in the simulation. The "Validation of the hydronic panel radiator model" section describes the validation of the hydronic panel radiator model versus available experimental measurements. The "Step response test between hydronic panel radiators with different location of connection pipes: comparison between the heat emitted" section describes the step response test between the hydronic radiator with different location of connection pipes. The "Brief overview of the building simulation model" section introduces a brief overview of the building simulation model. The "Simulation plan" section describes a simulation plan for the case investigated.

Method to calculate the efficiency factors for free heating surface (radiator) according to $\mathrm{EN}$ 15316-1,2-1 (2007) named as "German Method"

The efficiency method, explained in EN 15316-1 (2007), standardizes the heat input and the thermal losses towards the building envelope for a space heating system. The thermal losses are needed to calculate the efficiency factors of the space heating system. The variation of thermal losses due to the climate, type of heating system and type of building structure are discussed later in the "Simulation plan" section. The thermal losses towards building envelope are as follows: heat loss due to non-uniform internal temperature distribution $\mathrm{Q}_{\mathrm{em}, \mathrm{str}}$ and heat loss due to the control strategy $Q_{e m, c t r l}$ as shown in Fig. 3a. $\mathrm{Q}_{\mathrm{em}, \mathrm{str}}$ is split between the heat loss resulting in an increased/decreased internal temperature nearby the boundaries of the control volume considered (the room) $\mathrm{Q}_{\mathrm{em}, \mathrm{str} 1}$, and the heat loss due to the emitter position $\mathrm{Q}_{\mathrm{em}, \mathrm{str} 2}$.

$\mathrm{Q}_{\mathrm{em}, \mathrm{str}}$ refers to the heat loss adjacent to the ceiling $\mathrm{Q}_{\mathrm{em} \text {,cei }}$ where the indoor temperature is affected by stratification effect. In this context, the Technical Standard address also as stratification heat loss the

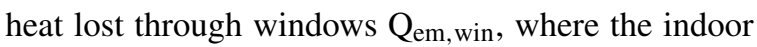
temperature is affected by cold surfaces. $\mathrm{Q}_{\mathrm{em}, \mathrm{str} 2}$ is referred to the heat loss towards back wall of the radiator accounted as convection and the radiation as shown in Fig. 3b.

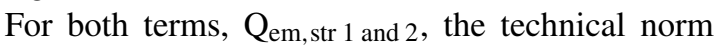
specifies how to calculate them by applying the general equation for the transmission heat lost as shown in Eq. 1.

$\mathrm{Q}_{\mathrm{em}, \mathrm{str}, \mathrm{i}}=\Sigma \mathrm{A}_{\mathrm{i}} \cdot \mathrm{U}_{\text {inc }, \mathrm{i}} \cdot\left(\mathrm{T}_{\text {air, inc }, \mathrm{i}}-\mathrm{T}_{\text {out }, \mathrm{i}}\right) \cdot \Delta \theta$

The technical standards consider the transmission losses because the mechanism of convection between the air volume and the internal surfaces, and the radiation among room internal surfaces happen inside of the control volume analysed. The example of control volume can be found in Fig. 3b. Equation 1 considers the locally increased/decreased of indoor temperature $T_{\text {int,inc }}$, and the locally increased/decreased of heat transfer coefficient calculated from the insulation material towards the internal surface $\mathrm{U}_{\text {inc. }}$. Most likely, Eq. 1 can be applied at the results of room models developed with computational fluid dynamic software. It is not obvious to calculate the locally increased/decreased of indoor temperature by using building energy simulation software. For this reason, $\mathrm{T}_{\text {cei }}$ and $\mathrm{T}_{\text {win }}$, the temperature of internal surface of the ceiling and of the window, replace $T_{\text {air,inc }}$ in Eq. 1 by using the same heat transfer coefficient $U_{i}$ of the structureconsidered. Special consideration is due to the increasing of indoor temperature nearby the ceiling. According to the Annex A.2 of EN 15316-1 (2007), the efficiency factor for over-temperature nearby the ceiling is of $0.95 \%$ with heating curve of $55 / 45^{\circ} \mathrm{C}$ and $\Delta \mathrm{T}=30 \mathrm{~K}$ for radiators. The increase of indoor temperature near the ceiling is considered constant throughout the simulation time. 


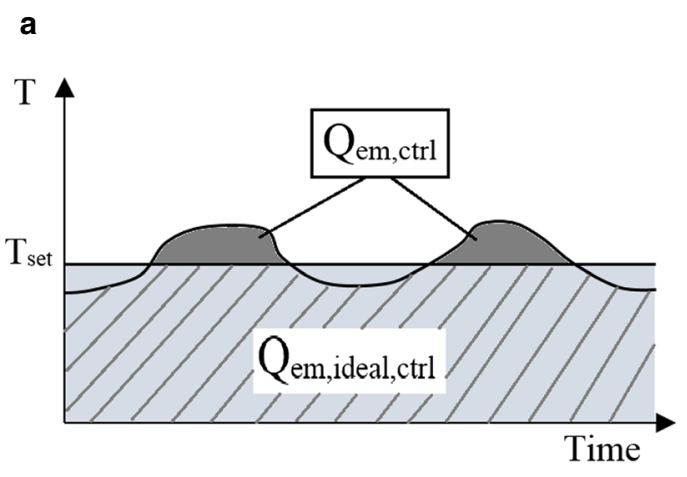

Fig. 3 Heat losses. a Control. b Stratification

The heat loss due to the control of indoor temperature $\mathrm{Q}_{\mathrm{ctrl}}$ refers to the non-recoverable heat over the room temperature set point. A non-ideal control causes variations and drifts around the prefixed set-point temperature due to the physical characteristics of control system, the heating system itself and the sensor location. In this paper, to simplify the problem the sensor only detects the behaviour of air temperature.

According to the standard EN (EN 15316-2-1 2007), the efficiency factors for stratification $\eta_{\mathrm{em}, \mathrm{str}, 1 \text { and2 and }}$ control $\eta_{\mathrm{em} \text {,ctr }}$ can be quantified with the ratio between the heat loss calculated with an ideal heating system over the heat loss of the real case as shown in Eq. $2 \mathrm{a}$ and $b$. The ideal case calculates the energy demand for heating the living space according to the EN 13790 (2008). The indoor temperature is kept constant (or approximately constant) over the heating period. The room is equipped with both ideal control and ideal heating system. This means that, the heating system does not consider eventual delays from the control, the heat stored in the heat emitter and the heat emitted from distribution pipes. The heat gains from sun, occupancy, electrical appliances, lighting and mechanical ventilation are the same for both real and ideal cases.

$$
\begin{aligned}
& \eta_{\mathrm{em}, \mathrm{str} 1 / 2}=\frac{\mathrm{Q}_{\mathrm{em}, \text { ideal }, \mathrm{str} 1 / 2}}{\mathrm{Q}_{\mathrm{em}, \mathrm{str} 1 / 2}} \\
& \eta_{\mathrm{em}, \mathrm{ctrl}}=\frac{\mathrm{Q}_{\mathrm{em}, \text { ideal }, \mathrm{ctrl}}}{\mathrm{Q}_{\mathrm{em}, \mathrm{ctrl}}}
\end{aligned}
$$

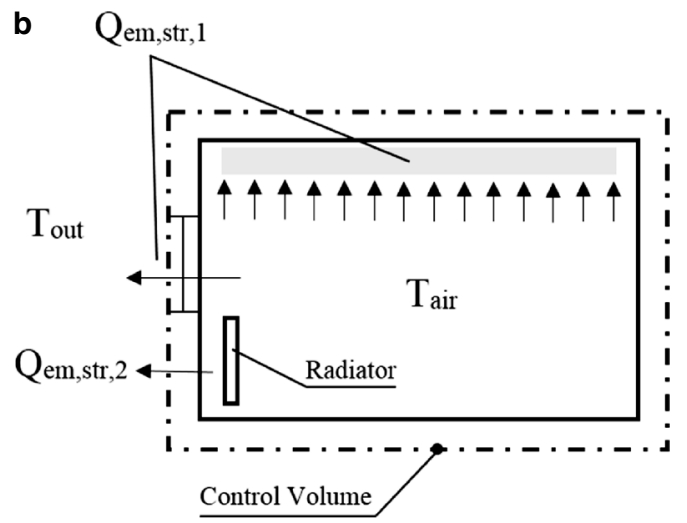

The total efficiency factor of the space heating system can be calculated by using the expression in Eq. 3 as states in Section 7.2 of EN (EN 15316-2-1 2007).

$$
\eta_{\mathrm{em}}=\frac{1}{4-\left(\eta_{\mathrm{em}, \mathrm{str}}+\eta_{\mathrm{em}, \mathrm{ctr}}+\eta_{\mathrm{em}, \mathrm{embed}}\right)}
$$

$\eta_{\mathrm{em}, \mathrm{embed}}$ has the value of 1 since the radiator does not have pipes embedded into the building structure. The term $\eta_{\mathrm{em} \text {,str }}$ is the average value between $\eta_{\mathrm{em} \text {,str1 }}$ and $\eta_{\mathrm{em}, \mathrm{str} 2}$.

Transient model of the hydronic panel radiator

The model is developed in junction with IDA ICE. The radiators are modelled as isothermal surface communicating with the zone model by temperature and heat flux interface. Therefore, one surface is modelled as the mean temperature of all metal. This simplification is due to the relatively high thermal conductivity of the metal in comparison with the fluid thermal conductivity. However, to capture the dynamic performance, the radiator fluid is modelled with several elements connected in series. The radiator thermal characteristics (nominal power, the power n, etc.) are read from technical catalogue. The heat emitted from the radiator is estimated on the basis of the radiator thermal characteristics using the air temperature and the water drop temperature. Finally, the surface temperature is obtained on basis of the difference between the estimated heat emitted and the total heat transfer at the model interface.

The supply line is positioned at the top corner $\mathrm{T}_{\text {sup }}$, whereas the exhaust line is positioned at the opposite bottom corner $\mathrm{T}_{\text {exh }}$. The temperature of supply 
flow of the $i$-th element is the exhaust temperature of the (i-1)-th element. When $\mathrm{i}=1, \mathrm{~T}_{\text {fld, } 0}$ is the $\mathrm{T}_{\text {sup }}$ into the radiator. Thus, the heat flow supplied at each capacitance $\dot{\mathrm{Q}}_{\text {sup }, \mathrm{i}}$ can be identified as follows:

$\dot{Q}_{\text {sup }, \mathrm{i}}(\theta)=\dot{\mathrm{m}}_{\mathrm{fld}} \cdot \mathrm{c}_{\mathrm{fld}} \cdot\left(\mathrm{T}_{\mathrm{fld}, \mathrm{i}-1}(\theta)-\mathrm{T}_{\mathrm{fld}, \mathrm{i}}(\theta)\right)$

where $\dot{\mathrm{m}}_{\mathrm{fld}}$ is the mass flow rate of fluid supplied to the radiator, $c_{f l d}$ is the specific heat capacity and the fluid temperature $\mathrm{T}_{\mathrm{fld}, \mathrm{i}}$ at different $i$-th capacitance.

The model calculates the temperature of each fluid capacitance $T_{\text {fld, } i}$ as difference between the heat flow supplied $\dot{\mathrm{Q}}_{\text {sup }, \mathrm{i}}$ to each capacitance and the heat out of each fluid capacitance $\dot{\mathrm{Q}}_{\mathrm{fld}, \mathrm{i}}$ as shown in Eq. 5.

$\frac{\mathrm{C}_{\mathrm{fld}}}{\mathrm{nCap}} \cdot \frac{\mathrm{dT}_{\mathrm{fld}, \mathrm{i}}(\theta)}{\mathrm{d} \theta}=\dot{\mathrm{Q}}_{\text {sup }, i}(\theta)-\dot{\mathrm{Q}}_{f l d, i}(\theta)$

where $\mathrm{C}_{\mathrm{fld}}=\mathrm{M}_{\mathrm{fld}} \cdot \mathrm{c}_{\mathrm{fld}}$, is the total capacitance of the fluid inside the radiator and nCap is the number of capacitance.

The model calculates the heat loss from the fluid $\dot{\mathrm{Q}}_{\text {fld }, \mathrm{i}}$ as shown in Eq. 6 .

$\dot{\mathrm{Q}}_{\mathrm{fld}, \mathrm{i}}(\theta)=\frac{\mathrm{K}_{\mathrm{tot}}}{\mathrm{nCap}} \cdot\left(\mathrm{T}_{\mathrm{fld}, \mathrm{i}}(\theta)-\mathrm{T}_{\mathrm{air}}(\theta)\right)$

where the total/equivalent heat transfer coefficient of the radiator $\mathrm{K}_{\text {tot }}$ is to Eq. 7 .

$\mathrm{K}_{\mathrm{tot}}=\frac{\dot{Q}_{N} \cdot\left(\frac{\Delta T_{l n, i}}{\Delta T_{l n, N}}\right)^{n}}{L \cdot H \cdot\left|\left(T_{f l d, i}(\theta)-T_{\text {air }}(\theta)\right)\right|}$

$\mathrm{L}$ and $\mathrm{H}$ are the radiator geometric parameters, length and height, and $\dot{Q}_{N}$ is total heat emitted by the hydronic panel radiator at nominal condition.

The logarithmic temperature difference in Eq. 7 is computed in Eq. 8.

$\Delta \mathrm{T}_{\ln , \mathrm{i}}(\theta)=\frac{\mathrm{T}_{\mathrm{fld}, \mathrm{i}}(\theta)-\mathrm{T}_{\mathrm{fld}, \mathrm{i}+1}(\theta)}{\ln \frac{\mathrm{T}_{\mathrm{fld}, \mathrm{i}}(\theta)-\mathrm{T}_{\text {air }}(\theta)}{\mathrm{T}_{\mathrm{fld}, \mathrm{i}+1}(\theta)-\mathrm{T}_{\text {air }}(\theta)}}$

Equation 8 cannot be solved if the ratio between the differences of temperature fluid-air is equal to 1 . Thus, Eq. 8 has to be replaced with the arithmetic temperature difference as shown in Eq. 9.

$\Delta \mathrm{T}_{\mathrm{i}}=\frac{\mathrm{T}_{\mathrm{fld}, \mathrm{i}}(\theta)+\mathrm{T}_{\mathrm{fld}, \mathrm{i}+1}(\theta)}{2}-\mathrm{T}_{\text {air }}(\theta)$

The logarithmic temperature difference at nominal condition $\Delta \mathrm{T}_{\ln , \mathrm{N}}$ is computed as in Eq. 8 with fluid and air nominal condition.

The model calculates the temperature of radiator surface $\mathrm{T}_{\text {surf }}$ as difference between the total heat loss from the fluid capacitances $\Sigma_{i=1}^{n C a p} \dot{\mathrm{Q}}_{\mathrm{fld}, \mathrm{i}}$ and the total heat emitted towards the surroundings $\dot{\mathrm{Q}}_{\text {tot }}$ as shown in Eq. 10.

$\mathrm{C}_{\text {met }} \cdot \frac{\mathrm{dT}_{\text {surf }}(\theta)}{\mathrm{d} \theta}=\Sigma_{\mathrm{i}=1}^{\mathrm{nCap}} \dot{\mathrm{Q}}_{\mathrm{fld}, \mathrm{i}}(\theta)-\dot{Q}_{\text {tot }}(\theta)$

where $\mathrm{C}_{\text {met }}$ is the capacitance of the metal part of the hydronic panel radiator, and $\mathrm{T}_{\text {surf }}$ is the mean surface temperature of the heat emitter.

The radiator model calculates the total heat transfer from the surface towards the surroundings $\dot{\mathrm{Q}}_{\text {tot }}$ in junction with with the zone model expressed as in Eq. 11. The interface between models is the longwave radiation exchanged between radiator surface and surrounding surfaces and convection at the radiator surface with room air temperature node.

$\dot{\mathrm{Q}}_{\text {tot }}(\theta) \propto\left(\mathrm{T}_{\text {surf }}(\theta)-\mathrm{T}_{\text {air }}(\theta)\right)^{\mathrm{n}}$

The total heat released into the thermal zone is split into three components as shown in Fig. 4 the heat towards back wall $\dot{Q}_{\text {back-wall }}$, the convective heat $\dot{\mathrm{Q}}_{\text {conv }}$, and the heat towards the zone $\dot{\mathrm{Q}}_{\text {front. }}$ Equation 12 shows this heat balance.

$\dot{\mathrm{Q}}_{\text {conv }}(\theta)=\dot{\mathrm{Q}}_{\text {tot }}(\theta)-\dot{\mathrm{Q}}_{\text {front }}(\theta)-\dot{\mathrm{Q}}_{\text {back-wall }}(\theta)$

The heat towards the back wall is driven by radiation and convection. In this paper, we approximate the heat lost with the mechanism of natural convection. The mechanism of heat transfer by natural convection towards radiator back wall depends on the temperature of back wall $\mathrm{T}_{\text {back-wall, the air temperature in }}$ the channel, the channel size $\mathrm{b}$ and its height $\mathrm{H}$. These parameters determine the Nusselt number $\mathrm{Nu}$ as shown in Eq. 13 according to Nevander and Elmarsson (1981) and Isfaelt and Peterson (1969).

$\mathrm{Nu}=\alpha \cdot\left(\mathrm{Gr} \cdot \operatorname{Pr} \cdot \frac{\mathrm{b}}{\mathrm{H}}\right)^{\beta}$

The estimating of the heat transfer coefficient by convection between the radiator and its back wall is shown in Eq. 14.

$\mathrm{h}_{\text {back-wall }}=\mathrm{Nu} \cdot \frac{\lambda_{\text {air }}}{\mathrm{b}}$

where $\lambda_{\text {air }}$ is the air heat conductivity.

Average values of temperature back wall, air temperature, thickness and length of the channel give an average heat transfer coefficient by convection towards radiator back-wall of $3 \mathrm{Wm}^{-2} \mathrm{~K}^{-1}$. The heat transfer coefficient by convection is assumed constant 

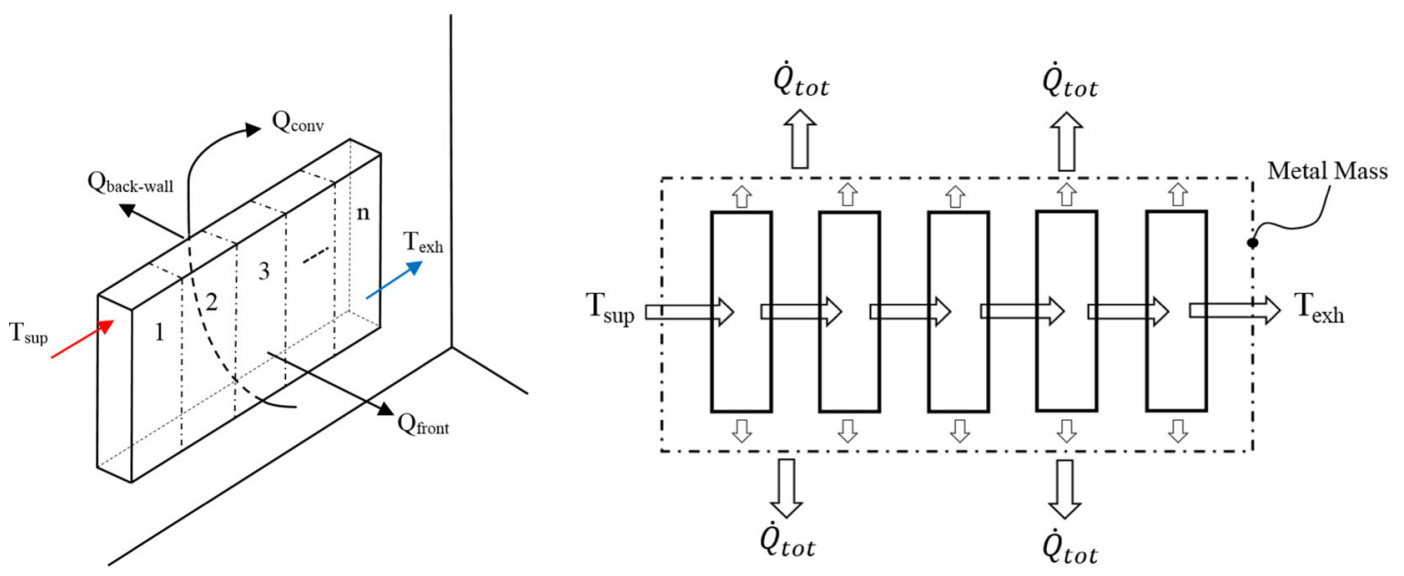

Fig. 4 Radiator schema with connection pipes located on opposite side

throughout the simulation. The heat loss towards the back wall is calculated as shown in Eq. 15.

$$
\dot{\mathrm{Q}}_{\text {back-wall }}(\theta)=\mathrm{h}_{\text {back-wall }} \cdot \mathrm{A} \cdot\left(\mathrm{T}_{\text {surf }}(\theta)-\mathrm{T}_{\text {back-wall }}(\theta)\right)
$$

The convective heat $\dot{\mathrm{Q}}_{\mathrm{conv}}$ is the heat released by the hydronic panel radiator in the room by the convective mechanism of circulation of indoor air. The indoor air circulates in the room, it enters in the channel between the radiator and its back wall and then it rises to the ceiling.

$\dot{\mathrm{Q}}_{\text {conv }}$ is calculated as the difference among the other known terms of Eq. 12 since $\dot{\mathrm{Q}}_{\text {front }}$ is computed in the zone model.

\section{Validation of the hydronic panel radiator model}

The validation of the hydronic panel radiator model is performed by comparing the simulated temperature of the exhaust flow during the charging phase and heat emitted when the steady state condition is achieved with the avialable experimental measurements in Stephan (1991).

Stephan (1991) has made a step response test of the hydronic panel radiator subjected to the sudden increase of the mass flow rate. The experiment is conducted in a booth which follows the technical characteristic listed in the standard DIN 4704 nowadays replaced with EN 442-2 (2014). The technical standard aims the measuring of the hydronic panel radiator thermal output by specifying the laboratory arrangements and testing methods.

For measuring the thermal output of the hydronic panel radiator, the temperature of indoor air is kept constant throughout the test by complying the steadystate conditions. To ensure a constant profile of indoor air, the booth is equipped with a cooling system integrated in each booth surface. The integrated cooling system enables to control the temperature of each booth surface (unless the surface on the back wall of the radiator) by fulfilling the steady-state conditions of the test.

Each booth's structure is made by sandwich panels. The sandwich panel consists of three layers: a steel panel with integrated the cooling system, insulating foam $(80 \mathrm{~mm}$ of thickness with thermal resistance of $2.5 \mathrm{~m}^{2} \mathrm{KW}^{-1}$ ) and an external steel sheet. The wall behind the hydronic panel radiator has the same sandwich panel but without the cooling system. The cooling system shall be designed to limit the temperature difference occurring among the cooled internal surfaces in the range of $\pm 0.5 \mathrm{~K}$. To ensure this, each panel shall be supplied with a mass flow rate of at least $80 \mathrm{kgh}^{-1}$ per each $\mathrm{m}^{2}$ of surface. The booth has two holes in the walls to guarantee water and electric connections between the hydronic panel radiator and outside the room. Figure 5 shows a schema of the booth and cooling system taken from EN 442-2 (2014).

A method to estimate the heat emitted from the hydronic panel radiator is the weighing method. The weighing method consists in the calculation of the 
Fig. 5 Booth and cooling system. Image taken from EN 442-2

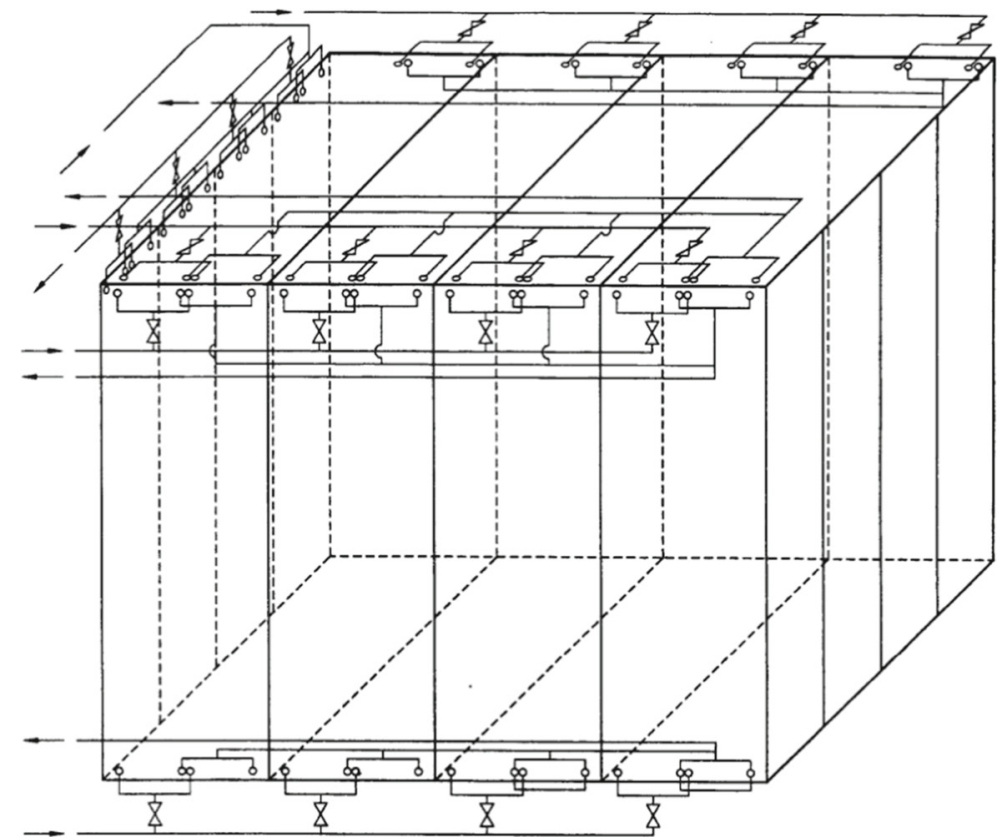

difference of enthalpy between the supply (inlet) and return (outlet) of the fluid multiplied for the mass flow rate. The enthalpy of the fluid at pressure and temperature measured in the test is known from tabulated values.

The hydronic panel radiator considered in Stephan (1991)'s experiment has the nominal parameters listed in Table 1 with connection pipes located on opposite side.

The hydronic panel radiator model has the same technical characteristics listed in Table 1. The experimental measurements and the simulated results are compared in Fig. 6 in terms of temperature of exhaust flow against the time.

The difference of the heat emitted between experimental measurements and simulated results is of $3.75 \%$ when the steady state condition is achieved.

Table 1 Nominal condition of hydronic panel radiator

\begin{tabular}{lll}
\hline Characteristic & Symbol & Value \\
\hline Nominal heat emitted & $\dot{\mathrm{Q}}_{\mathrm{N}}$ & $1245 \mathrm{~W}$ \\
Exponent & $\mathrm{n}$ & 1.25 \\
Metal mass & $\mathrm{M}_{\text {met }}$ & $18.7 \mathrm{~kg}$ \\
Fluid mass & $\mathrm{M}_{\mathrm{fld}}$ & $2.4 \mathrm{~kg}$ \\
Nominal mass flow rate & $\dot{\mathrm{m}}_{\mathrm{N}}$ & $1.484 \times 10^{-2} \mathrm{kgs}^{-1}$ \\
Metal specific heat capacity & $\mathrm{c}_{\text {met }}$ & $477 \mathrm{Jkg}^{-1} \mathrm{~K}^{-1}$ \\
\hline
\end{tabular}

Step response test between hydronic panel radiators with different location of connection pipes: comparison between the heat emitted

The hydronic panel radiator is positioned in a room subjected to constant outdoor temperature kept at $-15^{\circ} \mathrm{C}$ throughout the simulation time. The choice to keep the outdoor temperature at $-15^{\circ} \mathrm{C}$ is random; in fact, it can be chosen another value (in general less than the value of supplied temperature to the radiator), but it has to be stable throughout the simulation time by avoiding disturbances on the system. The heat gains from electrical appliances, lighting, occupancy, wind intensity and the sun are turned off

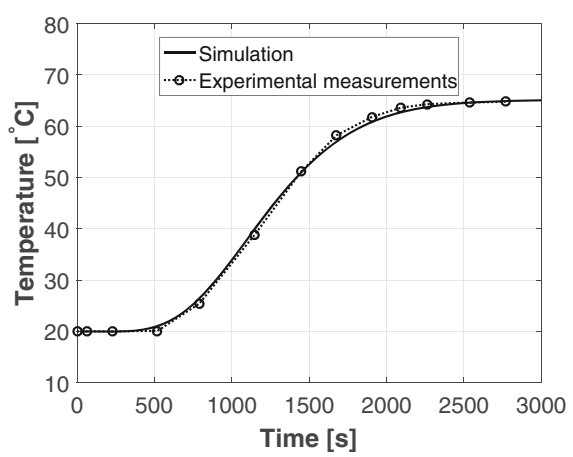

Fig. 6 Comparison between experimental measurements made by Stephan (1991) and simulated results for outlet water 


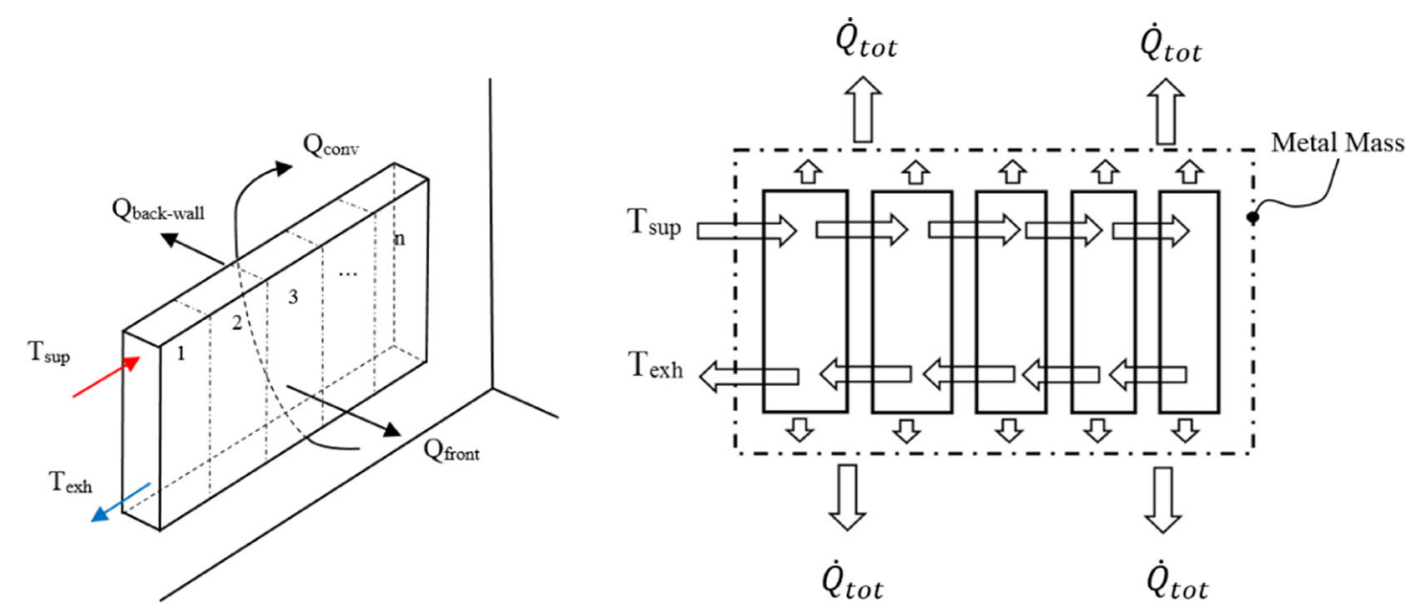

Fig. 7 Radiator schema with connection pipes located on the same side

during the test. The mass flow rate was increased to $0.01484 \mathrm{kgs}^{-1}$ at the simulation time $\theta=0$. Before this, the mass flow rate was of $2 \times 10^{-4} \mathrm{kgs}^{-1}$ and the temperature of the supply flow was kept constant at $83^{\circ} \mathrm{C}$.

The same test has been performed on the same type of hydronic panel radiator with connection pipes located on the same side. It is assumed that the fluid capacitance close to the connection pipes has a mass flow rate $10 \%$ higher than the furthest capacitance from the connection pipes. This type of hydronic radiator has as temperature of exhaust flow; the flow weighted average of exhaust temperature given by different flows in each element.

Figure 7 shows the radiator schema when connection pipes are located on the same side.

The total heat emitted from the hydronic panel radiator with different location of connection pipes is shown in Fig 8. It is possible to notice that radiators with connection pipes on the same side have slightly higher heat emitted than radiators with connection pipes located on opposite side. This means that, radiators with connection pipes located on the same side react quicker at variation of mass flow rate supplied in comparison with radiators with connection pipes located on the opposite side. In the long run, both heat emitted from the two solutions reach the same value.

Brief overview of the building simulation model

The simulation model consists of a room adjacent to other heated rooms. Ideally, no heat is transferred towards the other conditioned rooms, thus all the internal walls, ceiling and floor have set the adiabatic boundary condition. The performance of structure, fenestration, HVAC system are listed in Table 2. The room has a net floor surface area of $10 \mathrm{~m}^{2}$ with constant supply air flow at the temperature of $16^{\circ} \mathrm{C}$. The weekly schedules for occupancy, lighting and electrical appliances are standard; the room is occupied every day from 07.00 a.m. till 08.00 a.m. and from 05.00 p.m. till 08.00 p.m. during the heating period.

The room is provided with a mechanical ventilation system where the supply ventilation air flow is mixed with the indoor air by obtaining a roughly homogeneous temperature of the entire air volume. Calculations were made to design the size of pipes for

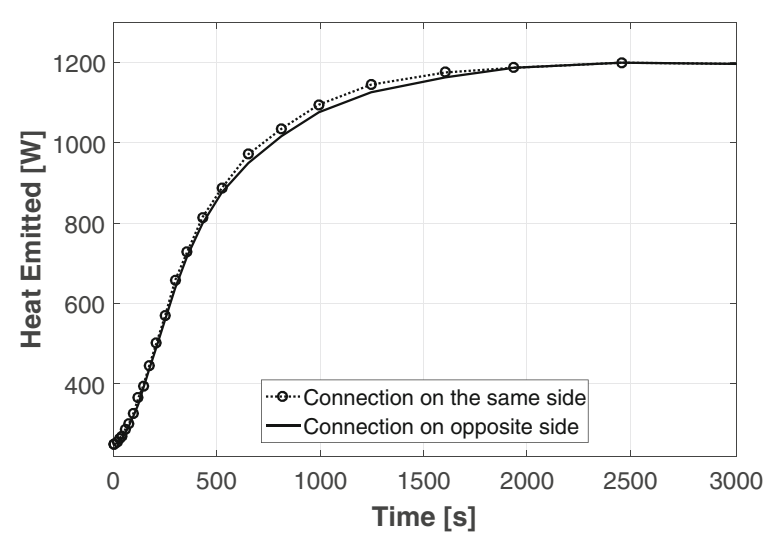

Fig. 8 Comparison heat emitted among radiators with different location of pipe connections 
Table 2 Building thermal characteristics

\begin{tabular}{llll}
\hline Characteristic & Description & Value & Surface/power \\
\hline $\mathrm{U}_{\text {value }}$ & Exterior wall & $0.15 \mathrm{WK}^{-1} \mathrm{~m}^{-2}$ & $5 \mathrm{~m}^{2}$ \\
Mechanical ventilation & Window & $1.1 \mathrm{WK}^{-1} \mathrm{~m}^{-2}$ & $1.5 \mathrm{~m}^{2}$ \\
& Supply & $201 \mathrm{~s}^{-1}$ & $0.6 \mathrm{ss}^{-1} \mathrm{~m}^{-2}$ \\
& Air leakage rate $q_{50 \mathrm{~Pa}}$ & $23 \mathrm{ss}^{-1}$ & $1 \mathrm{person}^{-2}$ \\
Internal gains & Exhaust & $8 \mathrm{Wm}^{-2}$ & $58 \mathrm{Wm}^{-2}$ \\
& Occupancy & & \\
\hline
\end{tabular}

the distribution system, the power required of circulation pumps, and the power required from the radiator and the power need of the air handling unit. The radiator is connected to the storage system which consists of a stratified hot tank. An electrical resistor inside the tank guarantees the required temperature at the supply fluid according to weather compensated heating curve. Circulation pumps work according to a constant curve of duty. The distribution pipes are supposed isolated and integrated in the building envelope. A schema of the building simulation model and HVAC system can be seen in Fig. 9.

\section{Simulation plan}

The following section explains how the simulations are planned to encompass the likely variations of thermal losses due to different building technical choices.
The simulation plan consists of sensitivity analysis on the building location, on the building envelope and on the characteristics of the heating system.

The first sensitivity analysis was carried out by locating the building in four different climates in Sweden: North, North-Central, South-Central and South. The climate affects the ratio between free heat and heat losses in the room space; thus, the heating can be decreased to meet the comfort requirements for occupants as shown by Bianco et al. (2016). In this scenario, the air humidity also plays a role as explained by Menghao (2011), because it affects the indoor climate and consequently the design of the HVAC system. The weather file used in the building simulation software is a synthetic weather file obtained from one hour based with values of outside dry-bulb temperature $\mathrm{T}_{\text {out }}$, relative humidity of air $\phi$, wind intensity in $x$ and $y$ direction and the cloudiness percentage $\%$.

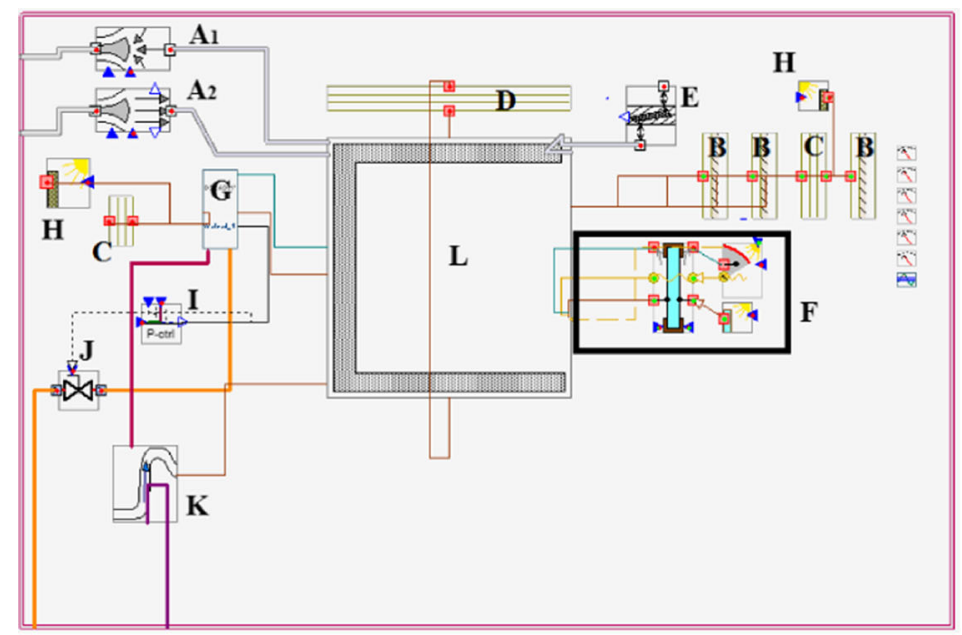

\section{Legend}

$A_{1}=$ Supply flow

A2 $=$ Exhaust flow

$\mathrm{B}=$ Adiabatic wall

$\mathrm{C}=$ External wall

$\mathrm{D}=$ Floor and ceiling

$\mathbf{E}=$ Leakage

$F=$ Window component

$\mathbf{G}=$ Radiator

$\mathrm{H}=$ Outdoor environment

I $=$ Control

$\mathbf{J}=$ Valve

$\mathrm{K}=$ Pipes

$\mathrm{L}=$ Thermal Zone

Fig. 9 Building simulation model of the room 
The values of direct $\mathrm{D}$ and diffuse $\mathrm{d}$ solar radiation are calculated according to Zhang-Huang model. The synthetic weather file is recorded in ASHRAE (2001) database and used in the commercial building simulation software IDA ICE vers. 4.7. Figures 10 and 11 show the monthly average outside temperature and direct solar radiation for each locality chosen.

The second sensitivity analysis was performed by changing the active thermal mass. The active thermal mass is the first material layer in contact with the indoor air taking also into account all the material layers till the insulation as shown in Brembilla et al. (2015b). The active thermal mass stores thermal energy which is released in the indoor space. Many authors have considered the advantages and drawbacks of changing the building thermal mass. Ghoreishi and Ali (2013) state that a heavyweight thermal mass can smooth sharp oscillations of indoor temperature by guaranteeing a stable room temperature. During heating seasons, the stored heat will be released in the conditioned space; whereas, during the cooling seasons, implemented night ventilation dissipates the heat stored. Masy et al. (2015) state that the active thermal mass also has a positive effect by load shifting of the electricity used. The author of the present paper has changed the internal layer of the external wall made by bricks $\left(\rho_{\text {brick }}=1500 \mathrm{kgm}^{-3}, \quad c_{\text {brick }}=1000 \mathrm{Jkg}^{-1} \mathrm{~K}^{-1}\right)$ to wood $\left(\rho_{\text {wood }}=600 \mathrm{kgm}^{-3}, \mathrm{c}_{\text {wood }}=700 \mathrm{Jkg}^{-1} \mathrm{~K}^{-1}\right)$ by adjusting the thickness of wood layer to have the same thermal transmittance for both heavy and lightweight structure. The same change happened for the brick layer of adiabatic walls adjacent to conditioned rooms and for the concrete layer in the floor and ceiling $\left(\rho_{\text {con }}=2300 \mathrm{kgm}^{-3}, \mathrm{c}_{\text {con }}=880 \mathrm{Jkg}^{-1} \mathrm{~K}^{-1}\right)$.

The third sensitivity analysis focused on the local control of the radiator. The local control was switched

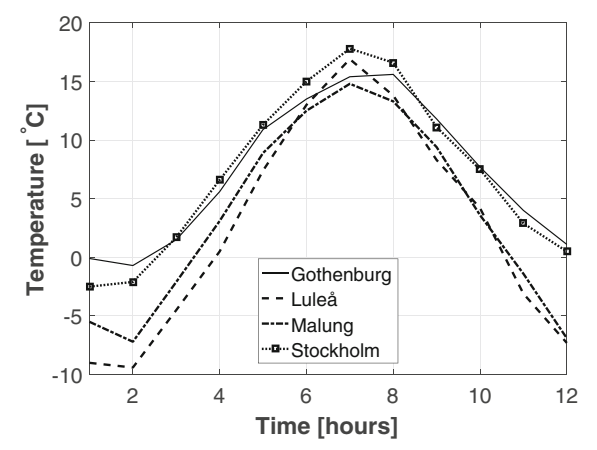

Fig. 10 Monthly average outside temperature

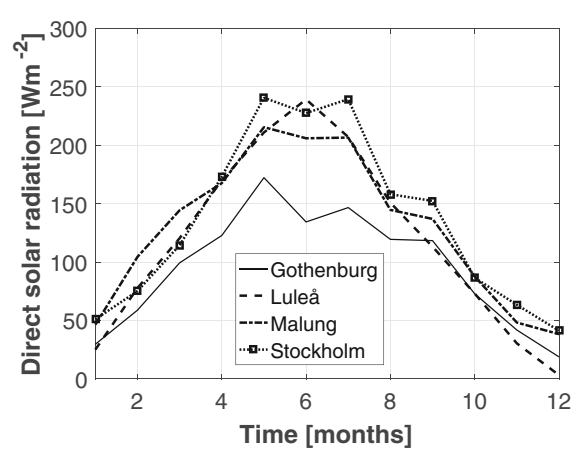

Fig. 11 Monthly average direct solar radiation onto horizontal surface

between $\mathrm{P}$ (proportional band with $\Delta \mathrm{T}=1 \mathrm{~K}$ first, and then with $\Delta \mathrm{T}=2 \mathrm{~K}$ ) and PI control. P control enables a proportional flow adjustment at the variation of indoor temperature when goes outside of the proportional band. PI control also guarantees an integration time that reduces the response of the system and it stabilizes the oscillations of indoor temperature as stated in Sanchis et al. (2010) and Qu and Zaheeruddin (2004).

The last sensitivity analysis was carried out by switching the connection pipes location. The connection pipes are first located on the same side of the radiator and then on the opposite side. All sensitivity analysis account of 48 real cases and 8 ideal cases. The ideal cases are set for each climate analysed and for both heavy and light-weight active thermal mass.

\section{Result and analysis}

Table 3 presents the results of efficiency factors for a space heating system equipped with hydronic panel radiator. The values in the table refer to the efficiency values calculated as explained in the "Method to calculate the efficiency factors for free heating surface (radiator) according to EN 15316-1,2-1 (2007) named as "German Method"" section. To be noticed, the term $\eta_{\text {str1 }}$ is the average efficiency between the efficiency factor for heat loss through the window and efficiency factor for the over-temperature nearby the ceiling. The results from IDA ICE simulation software are post processed by integrating the heat losses over the heating period as explained in Eq. 1 according to the trapezoidal rule. The length of heating period 
is assumed the same for all the cases analysed starting from the $1^{\text {st }}$ of September till the $30^{\text {th }}$ of May. The length of heating period varies in Sweden and it depends on the building type and location. In this paper, we use a standard length of heating period for all the cases analysed.

Table 3 can be used in a dual way, by assessing the efficiency factors for existing buildings or for driving the decisions of designers on technical choices which guarantee the highest efficiency for new buildings. In the first case, the designer needs to have the information about the building location, the weight of the active thermal mass and type of local control. For instance, a building located in Stockholm with heavyweight active thermal mass and $\mathrm{P}$ control $(\Delta \mathrm{T}=1 \mathrm{~K})$ with connection pipes located on the same side has as total efficiency factor of the space heating system the value of $0.95 \%$.
In the second case, the designer has to compare the efficiency factors between the type of local control used, the position of connection pipes and the type of active thermal mass for the same location chosen. For instance, for Stockholm is possible to achieve the total efficiency of the space heating system of $96 \%$ by using PI local control, same side location of connection pipes and light-weight mass of the building. It is possible to achieve the total efficiency of space heating system of $95 \%$ by choosing a $\mathrm{P}$ local control $\Delta \mathrm{T}=1 \mathrm{~K}$ ) heavy-weight active thermal mass with location of connection pipes on the same side.

\section{Discussion}

The transient model of radiator explained in the "Transient model of the hydronic panel radiator"

Table 3 Efficiency factors of a space heating system equipped with hydronic panel radiator heating curve $55 / 45^{\circ} \mathrm{C}$

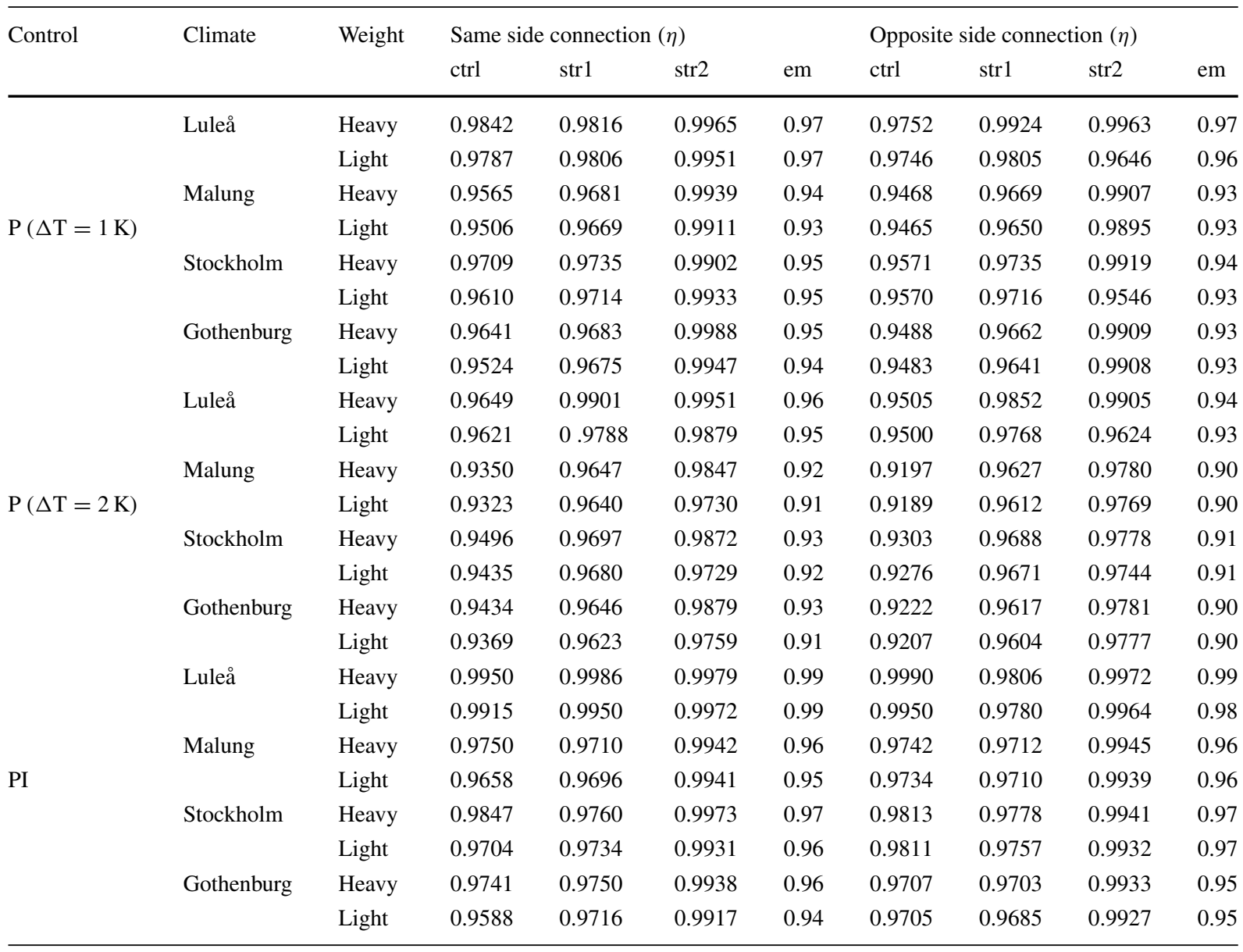


section can be improved by considering more capacitances for the metal part and by also considering the $y$ and $z$ dimensions. Another option is to use a simulation tool developed by Gritzki et al. (2007) which is able to model complex radiator geometry and several other details by means of the coupling of three software TRNSYS, PArallelNS and Fluent. Gritzki model enables to assess the efficiency factors among different sizes and types of radiators.

The heat transfer towards the back-wall of the radiator is approximated with the mechanism of natural convection. A combination of the mechanism of heat transfer by radiation and convection lets a better estimation of heat losses towards the back wall of radiators.

The model of hydronic panel radiator is validated in the "Validation of the hydronic panel radiator model" section versus experimental measurements in terms of temperature of exhaust flow. The results show a good agreement between the model and the measurements. The data of heat emitted by the hydronic panel radiator with the simulated results differ of $3.75 \%$.

The higher heat emitted from radiator with connection pipes located on the same side in Fig. 8 is likely caused by the amount of mass flow rate supplied in the first capacitance which is slightly higher in comparison with radiators with connection pipes located on the opposite side.

The building simulation model described in the "Brief overview of the building simulation model" section considers the mechanical ventilation. The supplied air from the mechanical ventilation system is mixed with the indoor air by resulting in an approximately homogeneous air temperature in the room air volume. The mechanical ventilation was chosen to minimize the deficiency of the commercial building energy simulation software used, since it does not consider an indoor temperature gradient in the room height. Thus, the author of the present paper uses tabulated values for computing the efficiency factor for over-temperature nearby the ceiling. The use of natural ventilation instead of mechanical ventilation will enhance the indoor temperature near the ceiling by increasing the heat loss. This fact cannot be effectively computed by the commercial building energy simulation software; thus, the author of the present paper avoid to present this type of solution in the results.

The simulation plan in the "Simulation plan" section does not consider sensitivity analysis on the heating curve. Many authors have studied the high potential in energy savings of the space heating system by applying modification at the heating curves. Vasek and Dolinay (2014) and Vasek and Dolinay (2013) presented a modification of the heating curve for multifamily buildings during rush hours. The results of these studies showed benefits in terms of lowering the amount of mass flow rate supplied to the thermal units. Another investigation made by Elkhuizen et al. (2003) showed the high potential in energy savings, up to $35 \%$, by using optimal heating and cooling curves for Dutch offices. This paper avoids to study the impact of the heating curve on the efficiency factors because the heating curve for hydronic panel radiators in Sweden is fixed at $55 / 45^{\circ} \mathrm{C}$. The heating curve has an impact on the efficiency factor for over-temperature nearby the ceiling as shown in Annex A.2 of the EN 15316-2-1 (2007).

The efficiency factors presented in EN 153161 and its sub-section will soon be replaced by the new upgrade of the norm. Right now, the project of recasting the Technical Standard is still under revision but available. The new Technical Standard will use another method to calculate the efficiency factors, named as "French Method". This method relies on the influence of different technical aspects of the HVAC system on the behaviour of indoor temperature. Technical details located outside of the room control volume, as the hydraulic balancing of the heating system, have an impact of the behaviour of indoor temperature named as "difference of temperature". The choice to use the "French Method" instead of the "German Method" is that the behaviour of indoor temperature can be easily detected in practice. In addition, several product standard relies on the behaviour of air temperature.

The efficiency factors in Table 3 have to be read in relative terms by comparing the results among each others. This means that, more detailed rooms and radiator models could give different results, but the general trend have to be the same. For instance, the local control detects the air temperature instead of the operative temperature which would lead to more accurate results by considering the radiative effect of wall surfaces.

The monthly average climatic variables in Figs. 10 and 11 show that the highest intensity of direct solar radiation is located in Stockholm while the lowest is located in Gothenburg from January till August 
and Luleå from September to December. The lowest average monthly outdoor temperature is recorded in Luleå while the highest average monthly temperature is for the city of Stockholm. It is possible to notice that Luleå has the highest seasonal difference range in temperature between winter and summer of about $23^{\circ} \mathrm{C}$. The diffuse radiation has similar values for all the climates considered. Furthermore, an important role plays the different latitude of each location which affects the inclination of sun rays when strike on surfaces. The climate affects the efficiency factors, in particular, in Northern climates (Luleå) the efficiency factors are higher than in Southern climates (Gothenburg) . This is because a likely reduction of the ratio between the free available heat in the room over the heat losses during the heating period. Thus, the local control devices have to make less operations while regulating the amount of mass flow rate supplied to the heat emitter. Less operations of the local control devices mean less adjustment of the mass flow rate supplied and consequently less variations of the heat emitted towards the environment. This fact will provide a more stable indoor temperature during the heating period which means higher efficiency factors.

It is possible to notice that, in Northern climates (Luleå), $\mathrm{P}$ control with proportional band $\Delta \mathrm{T}=2 \mathrm{~K}$ enables similar results of efficiency factors of PI control in Southern climates (Gothenburg). This means that, in Northern climates, simple local control devices allow to have efficiency factors comparable with more sophisticated control devices in Southern climates.

The efficiency factor for heat loss through windows is approximately the same in all the cases analysed with a slightly variation of about $2 \%$.

The heaviness of the active thermal masses has an impact on the efficiency factors. In fact, heavy-weight active thermal masses have better efficiency factors for control of the space heating system in the order of $1-2 \%$.

Lastly, the total efficiency factor for the space heating system $\eta_{\mathrm{em}}$ is higher when the radiator is connected with pipes located on the same side of the heat emitter. The difference looks apparently not remarkable because sometimes it is possible to appreciate less than $1 \%$ of difference between efficiency factors of radiators with different location of connection pipes.

These results could be considered when designing low energy buildings, to have a more rational and comprehensive picture of how technical choices, can affect the efficiency factors of the space heating system.
This conclusion is valid when the room is the control volume considered in the calculations. In fact, the efficiency method can encompass building components outside the room such as the circulation pump. Technological aspects of where to locate the connection pipes in function of the building needs are not investigated in this paper.

\section{Conclusion}

The assessment of efficiency factors for hydronic panel radiators has been investigated for space heating system in different climates in Sweden. The efficiency factors can be considered when design low energy buildings to have a comprehensive picture of how technical choices, as the heaviness of active thermal mass, type of local control, can affect the efficiency factors of the space heating system. To ensure a detail information of efficiency factors, the hydronic radiator model enables to predict the heat emitted during the charging/discharging phases among radiators with different location of connection pipes. The outcomes of this paper is Table 3 which is an useful practical support for designers, researchers (in Sweden) who want to compare the building performance in terms of efficiency factors. As main results, (i) connection pipes located on the same side of the radiator enable higher efficiency factors (between 1 and 2\%) than connection pipes located on opposite side; (ii) in Swedish Northern climate, the local $\mathrm{P}$ control $(\Delta T=2 \mathrm{~K})$ enables similar efficiency factors than radiators located in Southern climates controlled by PI control; and (iii) heavy-weight active thermal masses allow higher efficiency factors than light-weight active thermal masses.

Acknowledgements The first author wishes to thank Per Sahlin for the course held at EQUA headquarters about IDA ICE simulation software, Patrick Skogqvist and Erkki Karjalainen for their assistance during the development of the project. The author thanks Mohsen Soleimani-Mohseni for reviewing 2500 words of the current article. The author wishes to thank Dr. Joachim Seifert from Technische Universität Dresden for the valuable discussion about the efficiency factors.

Open Access This article is distributed under the terms of the Creative Commons Attribution 4.0 International License (http:// creativecommons.org/licenses/by/4.0/), which permits unrestricted use, distribution, and reproduction in any medium, provided you give appropriate credit to the original author(s) 
and the source, provide a link to the Creative Commons license, and indicate if changes were made.

\section{References}

Brembilla, C., Lacoursiere, C., Soleimani-Mohseni, M., \& Olofsson, T. (2015a). Transient model of panel radiator. In Proceedings of the 14th International Conference of the International Building Performance Simulation Association IBPSA (pp. 2749-2756).

Brembilla, C., Lacoursiere, C., Soleimani-Mohseni, M., \& Olofsson, T. (2015b). Investigation of thermal parameters addressed to a building simulation model. In Proceedings of the 14th International Conference of the International Building Performance Simulation Association IBPSA (pp. 2749-2756).

EN 13790 (2008). Energy performance of buildings-calculation of energy use for space heating and cooling.

EN 15316-1 (2007). Heating systems in buildings-method for calculation of system energy requirements and system efficiencies-part 1: General.

EN 15316-2-1 (2007). Heating systems in buildings - method for calculation of system energy requirements and system efficiencies-part 2-1.

EN 442-2 (2014). Radiators and convectors-part 2: Test methods and rating.

ASHRAE (2001). American society of heating refrigerating and air-conditioning engineers, weather files. Atlanta, GA, USA.

Bianco, V., De Rosa, M., Scarpa, F., \& Tagliafico, L.A. (2016). Analysis of energy demand in residential buildings for different climates by means of dynamic simulation. International Journal of Ambient Energy, 37(2), 108-120. doi:10.1080/0143 0750.2014.907207.

Bring, A., Sahlin, P., \& Vuolle, M. (1999). Models for building indoor climate and energy simulations, a report of iea shc task 22: building energy tools. http://www.equa.se/ dncenter/T22Brep.pdf.

Elkhuizen, P.A., Peitsman, H.C., \& Wienk, W.J. (2003). A new design guideline for the heating and cooling curve in ahu units of hvac systems. Building Services Engineering Research \& Technology, 24(3), 191-202. doi:10.1191/0143624403bt 071oa.

Ghoreishi, H., \& Ali, M. (2013). Parametric study of thermal mass property of concrete buildings in US climate zones. Architectural Science Review, 56(2), 103-117. doi:10.1080/00038628.2012.729310.

Gritzki, R., Perschk, A., Rösler, M., \& Richter, W. (2007). Modeling of heating systems and radiators in combined simulation. In Proceedings of Clima 2007 WellBeing Indoors. ISSN 978-952-99898-2-9.
Holst, S. (1996). Models for radiator heating system. TRNSYS TYPE 161-162, München. trnsys.de/download/en/ts_type_ 361_362_320_en.pdf.

Isfaelt, E., \& Peterson, F. (1969). Väermeavgivning fraan radiatorers baksida. Byggnads-Ingenjoeren, 11-12, 40-43,70.

Jančik, L., \& Bašta, J. (2012). Fluid flow in panel radiator under various conditions-thermographic visualization. EPJ Web of Conferences, 25, 01031. doi:10.1051/epjconf/2012250 1031 .

Maivel, M., \& Kurnitski, J. (2014). Low temperature radiator heating distribution and emission efficiency in residential buildings. Energy and Buildings, 69, 224-236. doi:10.1016/j.enbuild.2013.10.030.

Masy, G., Georges, E., Verhelst, C., Lemort, V., \& André, P. (2015). Smart grid energy flexible buildings through the use of heat pumps and building thermal mass as energy storage in the belgian context. Science and Technology for the Built Environment, 21(6), 800-811. doi:10.1080/23744731.2015. 1035590.

Menghao, Q. (2011). Whole-building heat, air, and moisture transfer modeling for residential buildings in different climates. HVAC\&R Research, 17(5), 860-871. doi:10.1080/10789669.2011.582918.

Myers, G. (1971). Analytical methods in conduction heat transfer. McGraw- Hill 1st Edition: $800-811$.

Nevander, L.E., \& Elmarsson, B. (1981). Fukthandboken. teori. dimensionering konstruktion.

Qu, G., \& Zaheeruddin, M. (2004). Real-time tuning of pi controllers in hvac systems. International Journal of Energy Research, 28(15), 1313-1327. ISSN 1099-114X. doi:10.1002/er.1030.

Sanchis, R., Romero, J.A., \& Balaguer, P. (2010). Tuning of pid controllers based on simplified single parameter optimisation. International Journal of Control, 83(9), 1785-1798. doi:10.1080/00207179.2010.495162.

Stephan, W. (1991). System simulation, specification: radiator. International Energy Agency Annex 10: University of Stuttgart.

Tahersima, F., Stoustrup, J., Rasmussen, H., \& Nielsen, P.G. (2010). Thermal analysis of an hvac system with trv controlled hdronic radiator. pages 756-761. doi:10.1109/COASE.2010.5584535.

Tahersima, F., Stoustrup, J., \& Rasmussen, H. (2013). An analytical solution for stability-performance dilemma of hydronic radiators. Energy and Buildings, 64, 439-446.

Vasek, L., \& Dolinay, V. (2013). Time-based heating curve modification. Recent Researches in Electric Power and Energy Systemsl, 8, 226-229.

Vasek, L., \& Dolinay, V. (2014). Method of heating curve modification for rush hours in practical experiment. International Journal of System Applications, Engineering and Developmentl, 8, 2074-1308. ISSN. 